\title{
Sclerosing cholangitis associated with Crohn's disease and autoimmune haemolytic anaemia
}

\author{
Oron Eilam², Eran Goldin ${ }^{1}$, Daniel Shouval ${ }^{2}$, Tzvi Gimon ${ }^{3}$ and Chaim Brautbar ${ }^{4}$
}

Departments of ${ }^{1}$ Gastroenterology, ${ }^{2}$ Medicine, ${ }^{3}$ Surgery and ${ }^{4}$ Tissue Typing, Hadassah University Hospital, Jerusalem, Israel

\begin{abstract}
Summary: A middle-aged man was found to have autoimmune haemolytic anaemia. Seven years after the first manifestations of the anaemia, he developed jaundice without haemolysis and a diagnosis of primary sclerosing cholangitis was made by endoscopic retrograde cholangiography. Crohn's colitis was later confirmed by $\mathrm{X}$-rays and colonoscopy. This association is unique to the best of our knowledge and suggests that genetic and immunological mechanisms may be involved in the pathogenesis of these diseases.
\end{abstract}

\section{Introduction}

Previous reports have emphasized the association of inflammatory bowel disease and primary sclerosing cholangitis (PSC), mostly with ulcerative colitis. ${ }^{1-5}$ Autoimmune haemolytic anaemia was described in several cases of ulcerative colitis but not in Crohn's disease. ${ }^{6-26}$ Only two cases of autoimmune haemolytic anaemia together with PSC have been previously published. HLA-B8 phenotype was reported in $60 \%$ of PSC patients, compared with only $25 \%$ of controls, while HLADR3 was found in $70 \%$ of the patients. ${ }^{29}$ This common haplotype is also present in an increased prevalence in several autoimmune diseases. ${ }^{30}$

\section{Case report}

A 41 year old male engineer suffered from hepatitis $A$ at the age of 19 . For over 10 years he had recurrent, mild right upper quadrant abdominal pain. Liver function tests, complete blood count and cholecystography were carried out several times and proved normal.

In February 1982 he was hospitalized due to fatigue and jaundice. There was no history of fever, drug or alcohol ingestion.

Laboratory studies on admission disclosed haemoglobin $10.9 \mathrm{~g} / \mathrm{dl}$; mean corpuscular volume $105 \mathrm{fl}$, total bilirubin $32 \mu \mathrm{mol} / \mathrm{l}$, direct bilirubin

Correspondence: Eran Goldin, M.D., Gastrointestinal Unit, Hadassah University Hospital, PO Box 12000, Jerusalem, Israel 91120.

Accepted: 18 December 1992
$14 \mu \mathrm{mol} / \mathrm{l}$, haptoglobin below $50 \mathrm{mg} / \mathrm{dl}$. Bone marrow studies showed marked erythroid hyperplasia. Direct Coomb's test was strongly positive with the $\stackrel{\bar{\rho}}{\rightarrow}$ specific test to IgG highly positive and to anti- $-8 \overrightarrow{0} \overrightarrow{0}$ negative. Upper and lower bowel barium studie e proved normal.

Abdominal ultrasound and computed tom graphy, ANA, rheumatoid factor, cold agglutinins and Donath-Landsteiner antibodies were $\bar{O}$ negative. The diagnosis was idiopathic Coombs $\frac{\mathscr{\perp}}{\varnothing}$ positive autoimmune haemolytic anaemia and $\varrho$ treated with prednisone. There was a haemato- $\overrightarrow{\vec{O}}$ logical response but due to constant infections the 3 patient underwent splenectomy in August 1983. Steroids were then discontinued, but he still suffered occasional bouts of haemolysis.

In April 1989, jaundice appeared again without other symptoms. The haemoglobin was $12.8 \mathrm{~g} / \mathrm{dl}$, mean corpuscular volume $110 \mathrm{fl}$, platelets 670,000, bilirubin $470 \mu \mathrm{mol} / 1$ (normal up to 16 ), alkaline phosphatase 420 units (normal range up to 110), aspartate transaminase $74 \mathrm{U}$ (normal up to 40 ) and $\stackrel{9}{\triangle}$ alanine transaminase $87 \mathrm{U}$ (normal up to 53).

The patient underwent ultrasound examination which revealed some enlargement of the gall- $N$ bladder without stones. Endoscopic retrograde cholangiopancreatography disclosed a firm stric- $N$ ture in the common hepatic duct, strictures and $\omega$ dilatation in the intrahepatic ducts (Figure 1). A

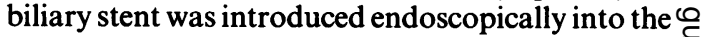
common bile duct through the main stricture and $\varnothing_{\mathscr{S}}$ the jaundice disappeared gradually.

In order to rule out cholangiocarcinoma, biop- 0 sies were taken from the stenotic area but no malignant changes were noted. 


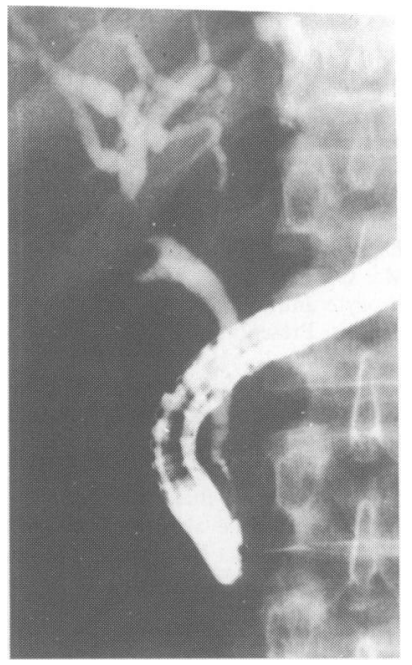

Figure 1 Endoscopic retrograde cholangiopancreatography showing a tight stricture of the common hepatic duct and several small strictures in intrahepatic bile ducts.

Between April and July 1989, the patient occasionally suffered from abdominal pain and from diarrhoea which was not bloody. At barium enema, colitis was suspected in transverse and ascending colon and, at colonoscopy, the mucosa of the caecum and ascending colon was granular with loss of the vascular appearance. No ulcers were seen. Histological examination showed colonic mucosa and submucosa sections with acute and chronic inflammation. The chronic inflammation was seen within the muscularis, but granulomas were not observed. The endoscopic, radiological and histological pictures were compatible with Crohn's colitis. HLA analysis revealed the following phenotypes: $\mathrm{A} 1, \mathrm{~A} 3, \mathrm{~B} 8, \mathrm{Bw} 58, \mathrm{Cw} 7, \mathrm{DR} 3$, DR7, DQw2, DRw52, DRw53.

\section{Discussion}

This patient illustrates a unique combination of autoimmune haemolytic anaemia, sclerosing cholangitis and Crohn's disease.

There is a recognized association between autoimmune haemolytic anaemia and ulcerative colitis, ${ }^{6-23}$ but not to our knowledge with Crohn's disease. The prevalence of auto-immune haemolytic anaemia was found to be one in 624 patients, ${ }^{24}$ and one in $479^{25}$ in patients with ulcerative colitis.

In a recent study of 112 consecutive patients with ulcerative colitis in two patients the Coombs test was positive $(1.82 \%)$. The immunoglobulin was IgG, complement was not found on the erythrocyte. These two patients shared HLA-Al with the patient presented here, but the other HLA antigens were different. ${ }^{26}$

The connections between sclerosing cholangitis (PSC) and inflammatory bowel disease is well known. Between 50 and $70 \%$ of the PSC patients had ulcerative colitis as well. ${ }^{1}$ On the other hand, the prevalence of Crohn's disease in PSC is very low and ranges between 0 and $4 \%$ in several series. ${ }^{2,3,5}$ Sclerosing cholangitis can precede the appearance of the inflammatory bowel disease and can appear even after total colectomy.

In a recent study, HLA was analysed in 29 (17 with ulcerative colitis) patients with primary sclerosing cholangitis before liver transplantation. ${ }^{4}$ Fifteen of the 29 patients with PSC (12 of the 17 with colitis) had a common haplotype: A1, B8, Cw7, DRw17, DR3, DQw2, DRw52a. In the remaining 14 patients (five with colitis) there was a loss of at least one of these antigens. However, all the patients were reported to carry the BRw52a subtype, based on the known linkage disequilibrium between the DRw52 allelic variant and DR3 . Our patient had in addition the above common haplotype.

The association between PSC and autoimmune haemolytic anaemia is extremely rare and there are only two reported cases. ${ }^{27,28}$ Neither case had inflammatory bowel disease.

In conclusion, we report a patient with three diseases: autoimmune haemolytic anaemia, primary sclerosing cholangitis and Crohn's disease. Several autoimmune diseases, such as chronic active hepatitis, type I diabetes mellitus, myasthenia gravis and thyrotoxicosis, which are associated with the production of autoantibodies, have an increased prevalence of HLA-B8 and DR3. ${ }^{29}$ Thus, the presence of an increased frequency of HLA-B8, DR3 and DRw52a alleles in PSC patients and also in our patient, and this particular combination of diseases suggests that both genetic and immunological mechanisms may be involved in their aetiology.

\section{References}

1. Lillemoe, K.D., Pitt, H.A. \& Cameron, J.L. Sclerosing cholangitis. Ann Surg 1987, 21: 65-92.

2. Wiesner, R.H., LaRusso, N.F., Ludwig, J. \& Dickson, R.E. Comparison of the clinicopathologic features of primary sclerosing cholangitis and primary biliary cirrhosis. Gastroenterology 1985, 88: 108-114.

3. Helzberg, J.H., Peterson, J.M. \& Boyer, J.L. Improved survival with primary sclerosing cholangitis. A review of clinicopathologic features and comparison of symptomatic and asymptomatic patients. Gastroenterology 1987, 92: 1869-1875. 
4. Prochazka, E.J., Terasaki, P.I., Park, M.S., Goldstein, L.I. \& Busuttil, R.W. Association of primary sclerosing cholangitis with HLA-DRw52a. $N$ Engl $J$ Med 1990, 322: 1842-1844.

5. Chapman, R.W., Arborgh, B.A. Modes, J.M. et al. Primary sclerosing cholangitis - A review of US, clinical features, cholangiography and hepatohistology. Gut 1980, 21: 870-877.

6. Keene, W.R. Uncommon abnormalities of blood associated with chronic ulcerative colitis. Med Clin North Am 1966, 50: 535.

7. Black, A.J., Eisinger, A.J.M.F., Loehry, C.A.E.H. \& Johnson, G.D. Ulcerative colitis with autoimmune haemolytic anaemia. Br Med J 1969, 2: 31.

8. Bardana, E.J., Jr \& Pirufsky, B. Autoimmune haemolytic anaemia and ulcerative colitis: a multisystem immunodeficiency disease? Int Arch Allergy 1970, 37: 325-336.

9. Goldstone, A.H. Autoimmune hemolytic anemia in ulcerative colitis. $\mathrm{Br}$ Med J 1974, 2: 556.

10. Gorst, D.W., Leyland, M.J. \& Delamore, I.W. Autoimmune haemolytic anaemia and ulcerative colitis. Postgrad Med J 1975, 51: 409-411.

11. Lorber, M., Schwartz, L.I. \& Wasserman, L.R. Association of antibody-coated red blood cells with ulcerative colitis. Am J Med 1955, 19: 887-894

12. Balint, J.A., Hammack, W.J. \& Patton, T.B. Autoimmune hemolytic anemia complicating ulcerative colitis. Gastroenterology 1962, 42: 740 .

13. Arner, O., Brohult, J., Karlson, R., Engstedt, L. \& Sallstrom, T. Autoimmune hemolytic anemia in ulcerative colitis, cured by colectomy. Acta Med Scand 1971, 189: 275-277.

14. Thomas, M., Homberg, J.C., Huguet, C.I. \& Ricordeau, P. Anemie hemolytique auto-immune au cours d'une rectocolite hemorragique. Nouv Presse Med 1972, 1: 2825-2826.

15. Altman, A.R., Maltz, C. \& Janowitz, H.D. Autoimmune hemolytic anemia in ulcerative colitis. Dig Dis Sci 1979, 24: 282-285.

16. Clements, D., Carter, C. \& Allan, R.N. Autoimmune haemolytic anaemia complicating ulcerative colitis. $\mathrm{Br} J$ Hosp Med 1988, 40: 72.

17. Lang, B., Weber, S. \& Maas, D. Autoimmune hemolytic anemia in ulcerative colitis. Report on 7 cases, possible treatment and review of the literature. Schweiz Med Wochenschr 1985, 115: 897-902.

18. Wodzinski, M.A. \& Lawrence, A.C. Severe Coombs positive autoimmune haemolytic anaemia associated with ulcerative colitis. Postgrad Med J 1985, 61: 261-262.
19. Mearin, F., Moreno-Otero, R., Rodriguez, S., Pivel, D.F. \& Pajarez, J.M. Ulcerative colitis, autoimmune hemolytic anemia and rectovaginal fistula. Arg Gastroenterol 1983, 20: $108-111$.

20. Raya-Munoz, J., Diez-Ruiz, A., Bonetti, A., Bermudez- $\subset$ Garcia, J.M., Salmeron-Escobar, J., Soto-Maz, J. \& PenaYanez, A. Ulcerative colitis associated with autoimmune hemolytic anemia, arterial thrombosis and dermal necrosis. Rev Esp Enferm Apar Dig 1983, 64: 435-440.

21. Airoldi, M., Giornazzi, L., Rosetta, A. \& Stefanetti, C. Anti-erythrocyte antibodies with and without hemolysis in ulcerative colitis. Presentation of 2 cases. Recent Prog Med 1986, 77: 527-529.

22. Basista, M.H. \& Roe, D.C. A case presentation of hemolytic anemia in ulcerative colitis and review of the literature. $A m J$ Gastroenterol 1986, 81: 990-992.

23. Aresu, G., Miescher, P.A. Mereu, S., Pascalis, L. \& Pia, G. Combined cyclosporin A-flucortalone in the therapy of ulcerative rectocolitis. An evaluation of the beneficial effects observed in a case complicated by severe immune hemolytic anemia. Clin Ter 1987, 122: 162-170.

24. Edwards, F.C. \& Truelove, S.C. The course and prognosis of ulcerative colitis. Gut 1964, 5: 1-15.

25. Ormerod, T.P. Observations on the incidence and cause of anaemia in ulcerative colitis. Gut 1967, 8: 107-114.

26. Poulsen, L.O., Freund, L., Lylloff, K. \& Grunnet, N. Positive Coombs test associated with ulcerative colitis. A prevalence $\delta$ study. Acta Med Scand 1988, 223: 75-78.

27. Moeller, D.D. Sclerosing cholangitis associated with autoimmune hemolytic anemia and hyperthyroidism. Am J Gastroenterol 1985, 80: 122-125.

28. Baker, S.S. \& Compton, C.C. A 17-year old boy with autoimmune hemolytic anemia and abnormal liver function. $N$ Engl J Med 1991, 324: 180-188.

29. Schrumpf, E., Fausa, O. \& Forre, O. HLA antigens an $\varnothing$ immunoregularity $\mathrm{T}$ cells in ulceritic colitis associated wit hepatobiliary disease. Scand J Gastroenterol 1982, 17 187-196.

30. Chapman, R.W. Role of immune factors in the pathogenesis of primary sclerosing cholangitis. Semin Liver Dis 1991, 1: $1-4$. 